\title{
Sampling Asian minorities to assess health and welfare
}

\author{
Russell Ecob, Rory Williams
}

\begin{abstract}
Study objective-The aims were (1) to sample a specified subgroup of the Asian minority; (2) to give proper representation to those outside the areas of concentration; and (3) to evaluate the costs and benefits of the method.
\end{abstract}

Design-Glasgow postcodes with varying concentrations of Asians were sampled, and 173 Asians aged $30-40$ were interviewed after household screening of 1439 Asian names identified on the electoral roll or valuation roll. Areas with few Asians, and households with two or more members aged $30-40$, were undersampled, and then reweighted.

Measurements and main results-Nurse measures of blood pressure, lung function, and body mass were taken, and selected interview measures of health and social background are reported. Substantial differences in blood pressure, reported health, and social background were revealed between Asians in areas of concentration and those in areas of dispersion. Loss in effective sample size due to undersampling and reweighting was $\mathbf{4 - 5 \%}$ in the case of the area sampling, $13 \%$ in the case of the household sampling. Losses of potential sample members through under registration were probably less than $6 \%$.

Conclusions-The present sampling method targets subgroups successfully, and improves on sampling in areas of concentration, in that it enables dispersed members of the minority, who differ in crucial indices of health and social position, to be represented. The costs of the method are acceptable.

Apart from the data supplied by maternity and mortality statistics, good representative information on the health and social situation of ethnic minorities in Britain is scarce, though both the health and welfare services, and the minorities themselves, are increasingly anxious to have it. Random sampling of minority populations is costly in time and labour, and as yet the large samples of ethnic minorities financed by major public resources have been concentrated on questions of education, employment, and housing. ${ }^{1}$

In the health field ethnicity data on maternity records, and the child registers compiled therefrom, have certainly made it easy in many places to obtain a representative sample of mothers or children. Again, with ethnic minorities which have distinctive names and high endogamy, such as those from $S$ Asia and the Chinese, the identification of naming patterns has become reliable enough to facilitate random sampling of the relevant minority population as a whole; ${ }^{23}$ and for other minorities who are distinguishable on sight the systematic sampling of local informants can yield the same result. ${ }^{1}$ But many questions about health and social welfare are necessarily specific to subgroups of the population, such as those defined by age, sex, or diagnostic condition, or need to be answered within samples which hold some of these factors constant. And here again the ordinary methods of random sampling by address or by the electoral roll become prohibitively expensive.

In the health field, responses to this problem have varied along fairly standard lines. One solution has been to sample in areas where the minority is known to be concentrated: indeed a standard work on sampling remarks that with minorities, "if a sufficiently large proportion ... is concentrated in sufficiently few districts, it may be justifiable to confine the survey to such districts, accepting the consequent bias". ${ }^{4}$ This bias obviously arises if members of the minority who are more dispersed differ in important and relevant ways. A second solution has been to sample from primary care registers, but we know that the quality of these can vary alarmingly, and even where address keeping is accurate for stable groups of the population it may not be so for mobile groups. A third approach, which at least attempts to remedy this last problem, is to sample from one or more general practices which have up to date computerised registers and which serve minority areas; but here the problem of sampling in areas of concentration arises again, and we need to know whether minority patients in such areas differ from their fellows elsewhere. Data on these points are presented in what follows.

The methods which we discuss below relate primarily to the "Asian" minority (ie, those whose ancestry is from the Indian subcontinent), or to any other minority which is identifiable by types of name. They set out, first, to sample the whole ethnic minority, and not just those living in areas of concentration; and they also seek, secondly, to do so in such a way as to enable subgroups to be identified cheaply and effectively. In both aims, our suggestions are essentially variants of the method developed for the third PSI survey, ${ }^{1}$ although we use name identification on the electoral roll, rather than address sampling and the use of local informants, to compile our primary list. Our use of this sampling frame compels us to consider, en route, problems of underrepresentation of the Asian 
minority on the roll, and the accuracy with which names can be identified. ${ }^{235}$ But this done, techniques of undersampling with statistical correction by reweighting can make it easier and cheaper to obtain data on dispersed members of the minority, and to identify subgroups by household screening without bias.

In what follows, we introduce these issues under four heads: ways of sampling areas of dispersion; problems and advantages of screening households from the electoral roll; procedures for selecting a target subgroup; and, as simply as possible, how appropriate statistical weights are constructed.

Finally our data are used to reveal similarities and differences in health and social measures between areas of concentration and areas of dispersion; and on this basis we evaluate the costs and benefits of our method against the prevailing use of samples from areas of concentration.

\section{Area sampling}

Where a genuine random sampling of areas is too expensive in cost or labour, savings may be made by undersampling areas where minority members are thin on the ground, and by oversampling individuals within these areas. Alternatively, where minority members are too few in such areas to achieve due proportion in the sample as a whole, it is possible to weight up, within limits, in the statistical analysis, by adjusting the sample proportions actually found to population proportions. While this latter tactic loses statistical precision it need not lose much, and together these two tactics provide cheap and useful data on minority members who live outside the areas of concentration.

In our own case, a sample of areas was already available. A large age specific comparison group of the general Clydeside urban population had already been identified from a random sample of 52 postcode sectors, of which 22 were in Glasgow. ${ }^{6}$ From 1981 census data for these 22 postcode sectors, it was apparent that some had virtually no residents who were born in India, Pakistan or Bangladesh: in fact $97 \%$ of such residents lived in 11 of these postcode sectors, their density varying from a maximum of $16 \%$ of the postcode sector population to a minimum of five per 1000 . We therefore took these 11 postcode sectors as our sample areas.

Using the same 1981 census data, we then divided all Glasgow postcode sectors into three strata containing approximately equal proportions of the Asian born population: (1) high density postcode sectors (Asian born $>6 \%$ ); (2) medium density postcode sectors (Asian born $3<6 \%$ ); (3) low density postcode sectors (Asian born $<3 \%$ )

Table I Proportions of Asians at various densities of concentration in Glasgow and in 11 selected Glasgow postcode sectors: Census 1981 compared with electoral roll 1986-7

\begin{tabular}{|c|c|c|c|}
\hline \multirow[b]{2}{*}{$\begin{array}{l}\text { Density of Asian } \\
\text { settlement }\end{array}$} & \multicolumn{2}{|c|}{$\begin{array}{l}\text { Census } 1981 \\
\text { born India, Pakistan, Bangladesh }\end{array}$} & \multirow{2}{*}{$\begin{array}{l}\text { Electoral roll } 1986 \\
\text { Asian name electors } \\
11 \text { postcode sectors } \\
(\%)\end{array}$} \\
\hline & $\begin{array}{l}\text { Glasgow } \\
(\%)\end{array}$ & $\begin{array}{l}11 \text { postcode sectors } \\
(\%)\end{array}$ & \\
\hline $\begin{array}{l}\text { High density } \\
\text { Medium density } \\
\text { Low density }\end{array}$ & $\begin{array}{l}34 \cdot 5 \\
30 \cdot 9 \\
34 \cdot 6\end{array}$ & $\begin{array}{l}51 \cdot 1 \\
29 \cdot 3 \\
19 \cdot 5\end{array}$ & $\begin{array}{l}49 \cdot 1 \\
26 \cdot 6 \\
24 \cdot 4\end{array}$ \\
\hline
\end{tabular}

We wished to use these data as a guide to proportions of current Asian electors at these levels of density, and we tested this by comparing our 11 postcode sectors for Asian born residents in 1981 and Asian name electors in 1986 (table I).

In these 11 sectors the proportion of Asian born residents and Asian name electors at these densities was similar; but when we compared the 11 sectors with the city wide data, we found that, in addition to excluding sectors with virtually no Asians, by chance these 11 undersampled sectors with 1-2\% Asians, and oversampled sectors with high densities of Asians-a tactic which can also be used deliberately to cut down travel costs and the costs of constructing sampling lists. ${ }^{1} \mathrm{We}$ remedied the situation by raising the sampling fraction for individuals in low density postcode sectors, and by reducing it for those in high density postcode sectors, and this came close to restoring the city wide proportions in each stratum. However we were also wishing to stratify by religion, and while corrective sampling fractions were successful with one religious stratum (Moslems), there were, in some postcode sectors, too few members of the other religious stratum (Sikhs and Hindus) to enable corrective sampling fractions to be used; hence the remaining deficit has to be corrected by statistical weighting, which is further described below.

This description of methods for area sampling already anticipates some of our procedures for screening households, and we now turn to these.

\section{Screening households}

In screening from the electoral roll, the first task is to identify minority members. Fortunately Asian first and second names can be identified on British listings with a high degree of sensitivity and specificity. In our case, though sensitivity could not be measured, specificity was likewise high: subsequent screening invalidated less than $1 \%$ of names identified as indicating Asian origin. Presumably our sensitivity is also unlikely to have been much different from previous reports (99$100 \%)^{2}$

The next task is to recover, if possible, any minority members who have been excluded from the roll. In identifying exclusions from the primary listing, a standard rule is to compare and synthesise other sampling lists. ${ }^{7}$ One such list can be compiled by asking electors to enumerate their own households, and data on non-electors in our Asian electors' households are presented later. To complement this, though, we also sought to identify whole households of non-electors, by comparing the valuation roll revised in April 1987 with the electoral roll revised in October 1986. Asian name resident occupiers on the valuation roll who did not appear on the earlier electoral roll were screened at the same sampling fractions, and to complete the revision thus achieved Asian electors who were found to have moved at screening were deleted from our sampling lists where an appropriate revision had occurred between the 1986 and 1987 valuation roll. Our sample frame was thus in effect the electoral roll of October 1986 updated where possible by the valuation roll of April 1987. This tactic enabled us to see whether, in addition to recent movers, there 
was a pool of less mobile Asian householders with no members at all on the electoral roll.

The final task in screening, once exclusions from the sampling list have been assessed and minimised in the way described, is to identify the target subgroup of the minority concerned. This may be done both by using information in the sampling list to stratify the sample before screening, and by eliciting further information during the screening itself. For example, before screening, we used analysis of names to stratify the sample by religion - a variable highly relevant to Asian health behaviour. Tested by a subsequent question to the interview sample about the religion they were born into, our analysis of household names predicted $100 \%$ of those born Moslems, and included only $2 \%$ who were born non-Moslems (one Sikh, one Christian). Similarly we predicted $99 \%$ of those born Sikhs or Hindus (taken together), and again included only $2 \%$ who were not (two Christians). These levels of accuracy were facilitated by having access to all names and forenames at the same address. Using this method of name analysis, then, we oversampled the relatively small Sikh and Hindu population of Glasgow in order to make our data relevant to the broad national situation, which is evenly balanced between Moslems and non-Moslems. ${ }^{1}$ At the same time, of course, we had the information to reweight our data to the religious distribution of Glasgow where this was needed. Naturally many other stratifying options would be equally valid.

By these procedures, we collected a screening sample of 1439 Asians aged 18 and over, representing a response rate of $81 \cdot 0 \%$. From this we identified our target subgroup (Asians aged $30-40$ ), by screening households for the age of household members. Age variation is especially troublesome with health and physical measures, and by holding it constant with an age specific comparison group, such as we had available to us, a small sample can be much more powerful.

\section{Sampling the target subgroup}

When sampling a subgroup, the advantages and disadvantages of doing so by household screening depend on the context. If we wish to ask how far members of the same Asian household share common experiences in terms of health or welfare, this method has obvious advantages, and there are ways of handling the interdependencies in such data. ${ }^{8}$ But if, as in our study, we are still at an earlier stage, and need to establish what levels of health and welfare Asians experience in general, interviewing all relevant members of the household may drastically reduce, for a given small sample, the number of independent data points obtained.

In a random sample of individuals, the chances of such interdependencies are negligible until the sampling fraction is very high indeed; but to avoid interdependencies when screening households, it is necessary to undersample in each household. The third PSI survey took two relevant members in each household of three or more and weighted for the rest, a tactic which loses little statistical efficiency through weighting, but which still halves the number of independent data points on all factors common to the married household. ${ }^{1}$ In smaller samples such as ours it may be more appropriate to take one relevant member in each household and accept the reduced efficiency of the statistical weighting, as it may be a price worth paying to minimise the still more reduced efficiency of a highly interdependent sample.

On the basis of these decisions, we emerged with an achieved subsample of 173 Asians aged $30-40$, representing a response rate of $80.5 \%$.

We now turn to the weighting requirements which have been indicated at this and other points in the discussion.

\section{Statistical reweighting}

In the strategies thus described we have identified a need for statistical weights in the following cases: (1) to correct a residual undersampling of low density areas; (2) to correct for selection of one respondent per household.

In applying these weights, logic demands that we apply first those weights (if any) which correct the sampling fraction used, and second those weights which adjust the resultant sample proportions to population proportions. We do these things first for the screening sample, which is adjusted to population proportions directly, and following that for the target subsample, which is adjusted to the weighted screening sample proportions, since these can estimate population proportions in the target subgroup.

WEIGHTING THE SCREENING SAMPLE

The only task here is to weight the sample proportions to population proportions. These population figures are stratified in two ways simultaneously, by density of Asian settlement
Table II Density of Asian settlement by religion: population proportions in each stratum

\begin{tabular}{|c|c|c|c|c|c|}
\hline $\begin{array}{l}\text { Density by } \\
\text { religion }\end{array}$ & $\begin{array}{l}\text { (a) } \\
\text { Population } \\
\text { proportion of } \\
\text { religious group } \\
\text { at each level of } \\
\text { density in the } 11 \\
\text { postcode sectors }\end{array}$ & $\begin{array}{l}\text { (b) } \\
\text { Population } \\
\text { proportion of } \\
\text { Asians at each } \\
\text { level of density } \\
\text { in Glasgow } \\
\text { (from table I) } \\
\end{array}$ & $\begin{array}{l}(c) \\
=(a) \times(b)\end{array}$ & $\begin{array}{l}\text { (d) } \\
\text { National } \\
\text { proportion of } \\
\text { religious group } \\
\text { (both } 0.5 \text { ) over } \\
\text { equivalent } \\
\text { proportion in (c) }\end{array}$ & $\begin{array}{l}\text { (e) } \\
\text { Target } \\
\text { population } \\
\text { proportions } \\
=(c) \times(d)\end{array}$ \\
\hline \multicolumn{6}{|l|}{ Moslems } \\
\hline high density & $0 \cdot 785$ & 0.345 & $0 \cdot 271$ & $0.5 / 0 \cdot 777$ & $0 \cdot 174$ \\
\hline \multirow{3}{*}{ low density } & 0.865 & 0.309 & $0 \cdot 267$ & $0.5 / 0.777$ & $0 \cdot 172$ \\
\hline & 0.690 & 0.346 & 0.239 & $0.5 / 0 \cdot 777$ & $\underline{0.154}$ \\
\hline & & & $\overline{0.777}$ & & $\overline{0.500}$ \\
\hline \multirow{6}{*}{$\begin{array}{l}\text { Non-Moslems } \\
\text { high density } \\
\text { medium density } \\
\text { low density }\end{array}$} & & & & & \\
\hline & 0.215 & 0.345 & 0.074 & $0.5 / 0 \cdot 223$ & $0 \cdot 166$ \\
\hline & 0.135 & 0.309 & 0.042 & $0.5 / 0.223$ & 0.094 \\
\hline & 0.310 & 0.346 & $0 \cdot 107$ & $0.5 / 0.223$ & $0 \cdot 240$ \\
\hline & & & $\overline{0.223}$ & & $\overline{0.500}$ \\
\hline & & & $\overline{1.000}$ & & $\overline{1.000}$ \\
\hline
\end{tabular}


(three strata), and by religion (two strata), making six cells in all. Table II gives calculations of the proportion of our postcode sectors' Asian population which would be found in each cell, if it was distributed by density in the same way as the Glasgow Asian population as a whole, and if it had the same proportions of Moslems and nonMoslems as are found nationally. This calculation represents the target proportions which our sample was intended as far as possible to reproduce. (The reweighting performed to match these data to the distribution of Moslems and non-Moslems locally in Glasgow is ignored here, though results from it are referred to where relevant later-details can be found elsewhere. ${ }^{9}$ )

Table III shows a comparison of the actual sample obtained. The chief discrepancy, as we indicated earlier, is that non-Moslems (ie, Sikhs and Hindus) are overrepresented in high density

Table III Screening sample: weights for density of Asian settlement by national religious composition

\begin{tabular}{llll}
\hline $\begin{array}{l}\text { Density } \\
\text { by religion }\end{array}$ & $\begin{array}{l}\text { Population } \\
\text { strata } \\
(\%)\end{array}$ & $\begin{array}{l}\text { Sample } \\
(\%)\end{array}$ & Weight \\
\hline $\begin{array}{l}\text { Moslems } \\
\text { high density }\end{array}$ & $17 \cdot 4$ & $20 \cdot 1$ & $17 \cdot 4 / 20 \cdot 1$ \\
medium density & $17 \cdot 2$ & $17 \cdot 8$ & $17 \cdot 2 / 17 \cdot 8$ \\
low density & $15 \cdot 4$ & $17 \cdot 4$ & $15 \cdot 4 / 17 \cdot 4$ \\
Non-Moslems & & & \\
high density & $16 \cdot 6$ & $20 \cdot 7$ & $16 \cdot 6 / 20 \cdot 7$ \\
medium density & $9 \cdot 4$ & $7 \cdot 7$ & $9 \cdot 4 / 7 \cdot 7$ \\
low density & $24 \cdot 0$ & $16 \cdot 3$ & $24 \cdot 0 / 16.3$ \\
& $100 \cdot 0$ & $100 \cdot 0$ & \\
& & & $1 \cdot 000$ \\
& Mean & $0 \cdot 236$ \\
& Standard deviation & $0 \cdot 80$ \\
& Minimum \\
& Maximum & & $1 \cdot 47$ \\
\hline
\end{tabular}

areas and underrepresented in low density areas; but there is also a slight tendency for Moslems to be overrepresented at all levels of density, because, as we discuss later, more non-electors were found among Moslems during household screening. The table then shows how this is corrected.

\begin{tabular}{lll}
\hline & Raw weight & $\begin{array}{l}\text { Standardised } \\
\text { weight } \\
=\text { WEIGHT 1 }\end{array}$ \\
\hline Mean & 1.509 & 1.000 \\
Standard deviation & 0.597 & 0.396 \\
Minimum & 1.00 & 0.66 \\
Maximum & 4.00 & 2.65 \\
\hline
\end{tabular}

Table $V$ Target subsample: weights for density of Asian settlement by national religious composition

\begin{tabular}{|c|c|c|c|c|}
\hline $\begin{array}{l}\text { Density } \\
\text { of settlement }\end{array}$ & $\begin{array}{l}\text { Population } \\
\text { (= weighted } \\
\text { screening } \\
\text { sample subgroup }) \\
(\%)\end{array}$ & $\begin{array}{l}\text { Sample } \\
\text { (weighted } \\
\text { by WEIGHT } 1 \\
\text { above) } \\
(\%) \\
\end{array}$ & Raw weight & $\begin{array}{l}\text { Standardised } \\
\text { weight }\end{array}$ \\
\hline $\begin{array}{l}\text { Moslems } \\
\text { high density } \\
\text { medium density } \\
\text { low density }\end{array}$ & $\begin{array}{l}15 \cdot 1 \\
15 \cdot 8 \\
16 \cdot 5\end{array}$ & $\begin{array}{l}16 \cdot 5 \\
16 \cdot 0 \\
17 \cdot 0\end{array}$ & $\begin{array}{l}15 \cdot 1 / 16 \cdot 5 \\
15 \cdot 8 / 16 \cdot 0 \\
16 \cdot 5 / 17 \cdot 0\end{array}$ & \\
\hline \multirow[t]{2}{*}{$\begin{array}{l}\text { Non-Moslems } \\
\text { high density } \\
\text { medium density } \\
\text { low density }\end{array}$} & $\begin{array}{r}15.5 \\
9.5 \\
27 \cdot 6 \\
100 \cdot 0\end{array}$ & $\begin{array}{r}20 \cdot 4 \\
9 \cdot 3 \\
20 \cdot 8 \\
100 \cdot 0\end{array}$ & $\begin{array}{c}15 \cdot 5 / 20 \cdot 4 \\
9 \cdot 5 / 9 \cdot 3 \\
27 \cdot 6 / 20 \cdot 8\end{array}$ & \\
\hline & \multicolumn{2}{|l|}{$\begin{array}{l}\text { Mean } \\
\text { Standard deviation } \\
\text { Minimum } \\
\text { Maximum }\end{array}$} & $\begin{array}{l}0.992 \\
0.183 \\
0.76 \\
1.33\end{array}$ & $\begin{array}{l}1 \cdot 000 \\
0 \cdot 185 \\
0 \cdot 77 \\
1 \cdot 34\end{array}$ \\
\hline
\end{tabular}

TARGET SUBSAMPLE: CORRECTING THE SAMPLING FRACTION

By taking one person aged $30-40$ in households where there were two or more, we effectively undersampled each set of households with a larger $\mathrm{N}$ of this subgroup by $1 / \mathrm{N}$. This is corrected statistically by reversing the fraction, and so the raw weight here is $\mathrm{N} / 1$. As the sum of these weighted cases varies in an arbitrary way from the sum of the actual cases, it may be intuitively helpful, when checking that the weighting is correct, if the weights are standardised to a mean of 1 and thus to a total equal to the actual sample size, before being related to any further weights required. A simple computing formula is available for this (see appendix 1). Accordingly table IV compares the raw weight, which varies from a minimum of one person aged $30-40$ per household to a maximum of four, with its standardised equivalent.

TARGET SUBSAMPLE: WEIGHTING TO POPULATION PROPORTIONS

Having corrected the sampling fraction, we now compare the sample figures thus weighted with the estimated population figures for the target subgroup. The figures of interest are, of course, those showing proportions by density of Asian settlement. The population estimate is derived, as we have said, from the screening sample figures for the subgroup, duly weighted as already described above. The raw and standardised weights derived are shown in table $\mathrm{V}$.

It remains only to estimate the increase in the standard error, and the consequent loss in effective sample size, which is incurred by the weighting. A simple computing formula is likewise available for this (see appendix 2) and results are shown in table VI.

The results of these weighting procedures can now be assessed, and the implications for sampling ethnic minorities shown, from the data we obtained.

Table VI Percentage loss in effective sample size for each weighting factor, and effective sample as percent of actual

\begin{tabular}{|c|c|c|}
\hline \multirow[b]{2}{*}{ Weighting factor } & \multicolumn{2}{|c|}{ Effective sample size } \\
\hline & $\%$ Loss & $\begin{array}{l}\text { As \% } \\
\text { of actual }\end{array}$ \\
\hline $\begin{array}{l}\text { Screening sample } \\
\text { weights for density of Asian } \\
\text { settlement }\end{array}$ & -5 & 95 \\
\hline $\begin{array}{l}\text { Target subsample } \\
\text { weights for undersampling } \\
\text { household members }\end{array}$ & -13 & 87 \\
\hline $\begin{array}{l}\text { weights for density or Asian } \\
\text { settlement }\end{array}$ & -4 & 83 \\
\hline
\end{tabular}

\section{Results}

In the introduction we listed several common ways of sampling ethnic minorities or subgroups thereof, and noted the risk of bias in the tendency of these methods to seek economy by sampling areas of high concentration. We have outlined our own alternative method of sampling from the electoral roll, which also, by seeking economy, introduces its own biases; but we have argued that these biases can be corrected. We have described ways of identifying non-electors; and we have 
described methods of statistical correction. We now present data showing variation in key variables by density of minority settlement; and then we summarise the extent of the corrections achieved to biases in our own method, together with the costs in loss of statistical power.

DATA

The key variables selected include physical measures taken by a trained nurse from the target subsample. These were chosen as being closely related to mortality, while remaining noninvasive. Blood pressure was measured using a Hawkesley random zero sphygmomanometer, after five minutes' rest and in a sitting position. Our data are based on the mean of two readings. Systolic pressures were plotted against diastolic, and doubt being cast on the measurements of one nurse, who saw only four cases, all four were excluded. Also, in computing the group means used below, one outlying case with extremely high values was excluded. Height was measured in metres and centimetres using Nivotoise stadiometers, weight in $\mathrm{kg}$ by portable electronic scales calibrated at the local trading standards office, and the resultant body mass index was determined as weight $\div$ height $^{2}$. Forced expiratory volume in $1 \mathrm{~s}$ was measured three times with a standard portable spirometer, and the maximum taken; in the absence of expected values specific to Asian populations, results are expressed as standard deviations from North American expected values in a disease free population by height, sex, and age. ${ }^{10}$ Normal lung function in Asians is known to fall well below these values.

The remaining variables record answers either to the limited screening questions, or questions with standardised and prepiloted translations, asked of the target subsample in the language of the respondent by training bilingual interviewers. Social background variables include the basic demography of age, sex, religion, and household size, all available from the large screened sample, together with economic measures from the target subsample. Since standard measures of social class require more interpretation for this population than is appropriate here, we have used other common indices relating to car ownership and to the house. In a minority where the great majority are owner-occupiers, our best summary indicator of house value is probably our observer's rating of external repair (characteristically worse than internal repair, and reflecting the limited control of Asian families over conditions in their shared tenements). Also, as an index of consumption, we record how many household durables were present out of a list of nine.

Health behaviour and reported health were recorded for the target subsample. In most of the measures of reported health the question asked is sufficiently obvious for purposes of the present comparison, with two exceptions. The 12 item General Health Questionnaire was used to give an indication of possible clinical levels of psychological malaise, ${ }^{11} 12$ each item scoring one when its negative aspect was experienced more frequently than usual; and a list of 10 common chronic conditions was one item used in assessing current health status. In the indices of health behaviour, the measures of drinking and smoking are obvious, while "strenuous" exercise was defined as lasting for at least 20 minutes and causing the respondent to get out of breath and sweat.

\section{RESULTS AND DISCUSSION}

Tables VII-IX show key health and social variables across the three categories of density in Asian settlement described earlier. The data in these tables are weighted to reflect the religious composition of the Asian population nationally, but, unless reported otherwise, significance levels and trends are similar when weighted to religious composition locally. Since our area strata represent an underlying continuous variable (density of settlement), statistics report tests for trend wherever the data suggest this possibility. Also, in the target subsample, statistics are listed where the likelihood of chance effects falls below $0 \cdot 10$, although we define only the 0.05 level as significant for both samples. This is because our subsample is too small to rule out area effects when results are non-significant, though it is sufficient to pick up a number of significant effects. We describe all these effects in as summary a fashion as possible, since the purpose of this paper is methodological, and descriptive and explanatory detail will be given in forthcoming papers.

The results are mixed, and in some respects not unfavourable to sampling areas of concentration, though in other respects they point to important reservations. They are not unfavourable, for example, in physical measures of body mass and lung function (table VII). Blood pressure, however, shown in the same table, is more problematic. We found significantly higher systolic pressures among Asians living in high
Table VII Glasgow Asians aged 30-40, 1987: selected physical measures by density of Asian settlement

\begin{tabular}{|c|c|c|c|c|c|}
\hline \multirow[b]{2}{*}{ Physical measures } & \multirow[b]{2}{*}{ All Asians } & \multicolumn{3}{|c|}{ Density of Asian settlement } & \multirow[b]{2}{*}{$p$} \\
\hline & & High & Medium & Low & \\
\hline Systolic BP-mean & $116 \cdot 3$ & $120 \cdot 8$ & $114 \cdot 8$ & $113 \cdot 7$ & 0.025 \\
\hline & 13.9 & $13 \cdot 0$ & $17 \cdot 3$ & $11 \cdot 7$ & \\
\hline $\begin{array}{c}\text { Diastolic BP-mean } \\
\text {-SD }\end{array}$ & $79 \cdot 9$ & $83 \cdot 1$ & $78 \cdot 2$ & $78 \cdot 5$ & 0.095 \\
\hline Mean arterial pressure ${ }^{\star}$-mean & $11 \cdot 9$ & $10 \cdot 5$ & $14 \cdot 2$ & $11 \cdot 2$ & \\
\hline$-\mathrm{SD}$ & $\begin{array}{l}92.0 \\
11.9\end{array}$ & $\begin{array}{l}95 \cdot 7 \\
10 \cdot 6\end{array}$ & $90 \cdot 4$ & $90 \cdot 2$ & $0 \cdot 046$ \\
\hline Body mass index-mean & $26 \cdot 2$ & $\begin{array}{l}10 \cdot 6 \\
26 \cdot 3\end{array}$ & $\begin{array}{l}14 \cdot 6 \\
27.5\end{array}$ & $10 \cdot 5$ & NS \\
\hline $\mathrm{FEV}_{\mathrm{l}}$ (standard deviation from predicted) & $5 \cdot 2$ & $5 \cdot 1$ & $\begin{array}{r}27 \cdot 3 \\
7 \cdot 2\end{array}$ & $\begin{array}{r}25 \cdot 4 \\
3 \cdot 7\end{array}$ & NS \\
\hline $\begin{array}{l}\text { - mean } \\
\text {-SD }\end{array}$ & $\begin{array}{r}-1.98 \\
1.02\end{array}$ & $\begin{array}{r}-2 \cdot 04 \\
1 \cdot 04\end{array}$ & $\begin{array}{r}-1.98 \\
1.13\end{array}$ & $\begin{array}{r}-1.93 \\
1.05\end{array}$ & NS \\
\hline Unweighted $\mathrm{N}$ & 157 & 50 & 46 & 61 & \\
\hline
\end{tabular}

$\mathrm{BP}=$ blood pressure

¿
diastolic $+1 / 3$ (systolic - diastolic) 
density areas, and we found a similar nonsignificant trend in diastolic pressures. A composite measure-mean arterial pressurereflecting both trends but weighted towards diastolic pressure, is thus also significant; and means in high density areas are 3-4 points higher than the overall mean for all three measures. These effects are however less pronounced among Moslems, and so when the table is weighted to the religious composition locally, which is predominantly Moslem, they become nonsignificant.

On measures of reported health there are several indications against sampling against areas of concentration (table VIII). In low density areas, significantly fewer Asians had chronic conditions, and fewer reported accidents. Subclinical depression was more frequent in medium and low density areas, though the difference is marginally non-significant, and potentially clinical levels of disturbance, as measured on the General Health Questionnaire, show a significant trend running parallel with the measure for subclinical depression in high and low density areas, though in between the parallelism is disrupted. Thus reported measures of overall physical and mental condition clearly indicate some area effects, with percentages in high density areas varying by $5-12$ points from the overall percentage in four out of seven measures.

On measures of health behaviour, on the other hand, there are fewer worries. The chief qualification is the area variation in medium density areas, which, though non-significant, still means that percentages in high density areas vary from the overall percentages by $5-9$ points. The

Table VIII Glasgow Asians aged 30-40, 1987: selected health and social background variables by density of Asian settlement

\begin{tabular}{|c|c|c|c|c|c|}
\hline \multirow[b]{2}{*}{ Key variables } & \multirow{2}{*}{$\begin{array}{l}\text { All } \\
\text { Asians } \\
(\%)\end{array}$} & \multicolumn{3}{|c|}{ Density of Asian settlement } & \multirow[b]{2}{*}{$p$} \\
\hline & & $\begin{array}{l}\text { High } \\
(\%)\end{array}$ & $\begin{array}{l}\text { Medium } \\
(\%)\end{array}$ & $\begin{array}{l}\text { Low } \\
(\%)\end{array}$ & \\
\hline $\begin{array}{l}\text { Health behaviour } \\
\text { never smoked } \\
\text { do not drink } \\
\text { take strenuous exercise }\end{array}$ & $\begin{array}{l}76 \\
74 \\
42\end{array}$ & $\begin{array}{l}71 \\
66 \\
51\end{array}$ & $\begin{array}{l}89 \\
85 \\
36\end{array}$ & $\begin{array}{l}72 \\
73 \\
39\end{array}$ & $\begin{array}{l}\text { NS } \\
\text { NS } \\
\text { NS }\end{array}$ \\
\hline $\begin{array}{l}\text { Reported health } \\
\text { health fair/poor } \\
\text { some days in bed last year } \\
\text { limiting longstanding illness } \\
1+\text { chronic conditions } \\
1+\text { accidents since age } 15 \\
\text { sometimes sad/depressed in last year } \\
\text { GHQ score } 4+\end{array}$ & $\begin{array}{l}49 \\
45 \\
16 \\
24 \\
28 \\
71 \\
12\end{array}$ & $\begin{array}{r}47 \\
42 \\
15 \\
34 \\
36 \\
59 \\
7\end{array}$ & $\begin{array}{r}50 \\
37 \\
24 \\
31 \\
39 \\
81 \\
9\end{array}$ & $\begin{array}{l}50 \\
50 \\
12 \\
14 \\
17 \\
75 \\
18\end{array}$ & $\begin{array}{l}\text { NS } \\
\text { NS } \\
\text { NS } \\
0.007 \\
0.015 \\
0.071 \\
0.042\end{array}$ \\
\hline $\begin{array}{l}\text { Social background } \\
\text { own car } \\
\text { own } 6+\text { household durables } \\
\text { home exterior in good repair }\end{array}$ & $\begin{array}{l}64 \\
43 \\
70\end{array}$ & $\begin{array}{l}64 \\
43 \\
72\end{array}$ & $\begin{array}{l}50 \\
23 \\
46\end{array}$ & $\begin{array}{l}71 \\
54 \\
81\end{array}$ & $\begin{array}{l}\text { NS } \\
0.022 \\
0.004\end{array}$ \\
\hline Unweighted N (=100\%) & 173 & 53 & 51 & 69 & \\
\hline
\end{tabular}

GHQ = General Health Questionnaire

Table IX Glasgow Asians 1987 (adult screening sample): social background variables by density of Asian settlement

\begin{tabular}{lccccc}
\hline & \multicolumn{4}{l}{$\begin{array}{l}\text { Density of } \\
\text { Asian settlement }\end{array}$} \\
\cline { 3 - 5 } Key social variables & $\begin{array}{l}\text { Asigh } \\
(\%)\end{array}$ & $\begin{array}{c}\text { Medium } \\
(\%)\end{array}$ & $\begin{array}{c}\text { Low } \\
(\%)\end{array}$ & \\
\hline Age 18-29 & 45 & 43 & 54 & 41 & 0.000 \\
Male & 52 & 53 & 51 & 51 & NS \\
Moslem & 50 & 51 & 66 & 38 & 0.000 \\
4+ Adults in household & 44 & 47 & 35 & 48 & 0.000 \\
Unweighted N $(=100 \%)$ & 1439 & 487 & 450 & 502 & \\
\hline
\end{tabular}

abstinence from drink among Asians in medium density areas is explained by the heavy local predominance of Moslems in these areas (see below).

Finally on social background variables there are marked indications against sampling in restricted areas. While there is no significant variation in the distribution of sexes by density of settlement, there is wide variation by religion, age, and household size (table IX). The medium density areas of Glasgow where Moslems are most strongly represented are characterised by a larger proportion of young adults, and by smaller households. Economic indicators also show marked differences in these areas (table VIII). The measure of external repair shows clearly that our medium density areas had poor housing, and it is evident from the number of household durables in these houses, at least when the religious groups are weighted equally as they are nationally, that the families occupying them were themselves relatively poor. Only in car ownership were the differences between areas nonsignificant on all weightings, though still with a similar trend.

On the whole, then, it is only in a minority of the present range of measures that areas of concentration seem broadly similar to areas of dispersion. With blood pressure, with many measures of reported health and social background, and possibly with some aspects of health behaviour, results in areas of greater dispersion may be markedly different.

Our own approach sets out to remedy these problems, but of course it has its own limitations. The first of these that we have mentioned is the risk of missing a substantial proportion of Asians not registered as electors.

Todd and Butcher ${ }^{5}$ found that in inner London $27 \%$ of Asians were not on the electoral roll. Further, in their national census postenumeration survey, they found that $31 \%$ of New Commonwealth citizens were not on the electoral roll, and $14 \%$ lived at addresses which were not on the roll either; while for citizens of countries outside the Commonwealth or Ireland, which would include citizens of Pakistan, the figures were still higher. Finally, they found that among those judged by the interviewer to be "coloured", New Commonwealth citizens differed little from UK citizens.

Our own results are much less extreme. In Glasgow $16 \%$ of our screening sample were not on the electoral roll, and only $4 \%$ lived at addresses which were not on the roll, and which were found from the valuation roll. There was a significantly higher proportion of non-electors among younger Asians and Moslems, and their tendency to attach themselves to existing households meant that there were significantly more non-electors in large households with three or more adults, and also in the Moslem dominated areas of the inner city where there was medium density settlement (table $\mathrm{X}$ ). But overall the proportions are quite moderate.

There are two possible explanations for these lower figures-that our screening methods failed to find a number of the Asians who were not on the electoral roll, or that non-registration is in fact lower in Glasgow. We consider each in turn. 
There is, first, no particular reason why our interviewers should have missed more than the OPCS (Office of Population Censuses and Surveys) interviewers of the non-electors who lived in the households of Asian electors. On the contrary, our interviewers had the advantage of being Asian themselves, and of speaking the respondent's first language. We may have missed a few non-electors who lived in the households of white electors, but in Glasgow Asian lodgers and tenants usually have Asian landlords. ${ }^{13}$ Hence if we missed non-electors, it was likely to be those who lived, not at the addresses of electors, but at addresses which were not on the electoral roll at all. In other words, it is a question of how well these latter non-electors were identified by our supplementary scan of Asians on the valuation roll.

Certainly, there were some problems with the valuation roll. While the Glasgow roll named occupiers as well as proprietors, occupiers were not always identified reliably, especially if the proprietor actually paid the rates, and this made it possible that occupiers with Asian names could sometimes have been missed. In addition, the annual revision was incomplete and slow moving: the great majority of Asians found on the valuation roll but not on the electoral roll were not eligible for our sample, being movers deleted from the electoral roll yet still not deleted from the (later) revision of the valuation roll.

However this is unlikely to be the whole story. The Asians we identified at addresses which were not on the electoral roll had the same ratio of owners to tenants (in the subgroup where we had these data) as those who were on the electoral roll,
Table $X$ Screening sample: categories with a significant excess of nonelectors

\begin{tabular}{lll}
\hline Characteristics & Non-electors & $p$ \\
\hline Age 18-29 & 20 & 0.000 \\
Moslem & 19 & 0.003 \\
3+ Adults in household & 19 & 0.002 \\
Areas of medium density Asian & 20 & 0.046 \\
$\quad$ settlement & 16 & \\
Overall & 16 & \\
\hline
\end{tabular}

Table XI Target subsample: effect of weight for undersampling household members (WEIGHT 1) and of weight for density of Asian settlement (WEIGHT 2) on key variables

\begin{tabular}{|c|c|c|c|c|}
\hline \multirow[b]{2}{*}{ Key variables } & \multicolumn{2}{|c|}{$\begin{array}{l}\% \text { Change in proportion } \\
\text { or mean ( } \% \text { of weighted } \\
\text { standard error) }\end{array}$} & \multicolumn{2}{|c|}{$\begin{array}{l}\% \text { Change in standard } \\
\text { error ( } \% \text { of weighted } \\
\text { standard error })\end{array}$} \\
\hline & WEIGHT 1 & WEIGHT 2 & WEIGHT 1 & WEIGHT 2 \\
\hline $\begin{array}{l}\text { Physical measures } \\
\text { systolic BP } \\
\text { diastolic BP } \\
\text { arterial pressure } \\
\text { body mass index } \\
\text { FEV }_{1}\end{array}$ & $\begin{array}{l}-26 \\
-11 \\
-18 \\
-40 \\
-34\end{array}$ & $\begin{array}{l}-40 \\
-38 \\
-41 \\
-9 \\
+24\end{array}$ & $\begin{array}{l}+8 \\
+11 \\
+10 \\
-4 \\
+8\end{array}$ & $\begin{array}{l}+1 \\
+2 \\
+1 \\
+1 \\
+2\end{array}$ \\
\hline $\begin{array}{l}\text { Reported health } \\
\text { health fair/poor } \\
\text { limiting longstanding illness } \\
1+\text { chronic conditions } \\
1+\text { accidents since age } 15 \\
\text { sometimes sad/depressed in last year } \\
\text { GHQ score } 4+\end{array}$ & $\begin{array}{l}+21 \\
-28 \\
-29 \\
+18 \\
+22 \\
-7\end{array}$ & $\begin{array}{l}+7 \\
-6 \\
-32 \\
-17 \\
+17 \\
+17\end{array}$ & $\begin{array}{l}+7 \\
+6 \\
+5 \\
+7 \\
+7 \\
+7\end{array}$ & $\begin{array}{r}+2 \\
0 \\
0 \\
+2 \\
+2 \\
+3\end{array}$ \\
\hline $\begin{array}{l}\text { Health behaviour } \\
\text { never smoked } \\
\text { do not drink } \\
\text { take strenuous exercise }\end{array}$ & $\begin{array}{l}+17 \\
+27 \\
-44\end{array}$ & $\begin{array}{l}+5 \\
+8 \\
-2\end{array}$ & $\begin{array}{l}+6 \\
+5 \\
+7\end{array}$ & $\begin{array}{l}+3 \\
+3 \\
+2\end{array}$ \\
\hline $\begin{array}{l}\text { Social variables } \\
\text { own car } \\
\text { own } 6+\text { household durables } \\
\text { house exterior in good repair }\end{array}$ & $\begin{array}{l}+59 \\
+40 \\
+12 \\
\end{array}$ & $\begin{array}{l}+26 \\
+30 \\
+42 \\
\end{array}$ & $\begin{array}{l}+5 \\
+7 \\
+7\end{array}$ & $\begin{array}{l}+2 \\
+2 \\
+2\end{array}$ \\
\hline
\end{tabular}

so there was in the end no apparent bias against tenant occupiers. Further, the census postenumeration survey showed that among New Commonwealth citizens, those who lived at addresses which were not on the electoral roll were fewer by a ratio of $14: 17$ than non-electors who lived at addresses of electors; and this ratio was similar in all categories of citizenship. On these figures, therefore, the $12 \%$ of unregistered Asians who lived with electors will have been accompanied by only around $10 \%$ who lived at addresses which were not on the electoral roll at all. Since we found $4 \%$ in this latter situation, at most $6 \%$ may have been missed. Thus even on these sceptical assumptions our total figure of non-electors should have been around $22 \%$-still less than Todd and Butcher's figure for inner London Asians (27\%) or for the census postenumeration survey's New Commonwealth citizens $(31 \%)$.

Our Glasgow results may well represent, therefore, a real qualification of the OPCS figures. Our screening sample was considerably larger (1439 Asians $v 92$ in inner London and a weighted figure of less than $100 \mathrm{New}$ Commonwealth citizens); it included the more stable and prosperous Asian residents who live outside the inner city; and in any case Scotland generally was found in the OPCS study to have the best registration rate for electors in Britain. It is probably these facts which explain why we found a smaller proportion of non-electors than they did; and either way the proportion of non-electors lost by our method is not large.

Now that valuation rolls are being phased out, an alternative way of picking up those living at addresses which are not on the electoral roll is by sampling the Postcode Address File, ${ }^{14}$ using the electoral roll wherever feasible to rule out addresses with known residents who are not Asian. Whether the extra trouble of consulting either of these additional resources (which can be considerable) is worth the extra coverage gained is for the investigator to decide on the merits of each case.

Along with non-elector respondents there is of course also the problem of elector non-response. This was at a moderate level $\left(19^{\circ}{ }_{0}\right)$ in our screening sample, nearly all of these nonrespondents having, we were told, recently moved. Here the valuation roll was of limited use, picking up only $16 \%$ of these movers, and reducing non-response by only $2 \cdot 6^{\circ}$.

The second hazard which our method incurs is some inevitable loss of precision due to the use of statistical weighting. Table XI shows the gains made by weighting, in the shape of changes in the means or proportions of key variables, shown as a percentage of the weighted standard error, and sets them against the losses, in the shape of increases in the standard error, again as a percentage of the weighted standard error. It is apparent that the increase in standard error is relatively small and fairly evenly distributed across variables for both weights, although the correction for undersampling household members (WEIGHT I) is more variable in this respect. The corresponding gains in corrections to sample means or proportions, meanwhile, are generally more substantial, although they should 
be evaluated in comparison with the interval of 2 standard errors which defines the 0.05 level of significance (corresponding to a $200 \%$ change in table XI). Social background variables tend to show the largest changes on either weight; but when one takes account of the cumulative effect of change in the same direction on both weights, there are also some marked changes in blood pressure (reduced in all aspects), and in reported health (reduced frequency of chronic conditions, raised frequency of subclinical depression), comparable with the similar or still greater changes in social variables (a shift towards greater prosperity in all respects). These data emphasise the importance of the statistical corrections required by our method even when much of the problem of covering dispersed members of a minority has been dealt with by adjusting sampling fractions.

\section{Conclusion}

Overall, then, we feel there are clear gains in the sampling strategy we have set out for Asian minorities. It enables dispersed members of the minority, who differ in crucial indices of health and social position, to be represented. And it enables small samples to be deployed more effectively, targeting subgroups which are identified through household screening.

The method applies most obviously to minorities which can be recognised by their name type on public lists, but other methods of recognition have been explored, as we noted in the introduction, such as visual recognition by local informants who are appropriately sampled. ${ }^{1}$ In either case, the same techniques of undersampling with statistical reweighting, and of household screening, can then be applied to the initial listing of minority households obtained.

The costs of the area sampling in this case-a $4-5 \%$ reduction in effective sample size due to the need to correct residual undersampling statistically (table VI) —can be put against the 5-6 point differences in mean blood pressure, and the differences of $20 \%$ or more on other health variables, revealed between high and medium or low density areas in tables VII-VIII. And the costs of household screening with undersampling of household members-a 13\% reduction in effective sample size (table VI)-can be put against the fact that, if we had interviewed all those aged $30-40$ in the household, we would have reduced our effective sample size on factors common to the household by $34 \%$.

The differences between areas of concentration and areas of dispersion which we have shown suggest that samples from areas of concentration need to be considered with an eye to the religious composition, built environment, and relative prosperity of the area chosen. Perhaps most important, comparisons made on such samples between the minority and the general population on questions of health or welfare will need to be carefully qualified with an eye to the same factors; and even when health and welfare measures which do not vary by density of settlement are in question, we should be cautious when using samples from areas of concentration about inferring links between the measure concerned and minority social and cultural characteristics, since many of these characteristics do vary by density of settlement. These comments do not in any way rule out the usefulness of such samples from densely settled areas in sensitising us to possible problems of health and welfare, and in generalising to similar areas elsewhere; but they point to the need for judgement and awareness of local factors in interpreting their findings, and especially to the importance, by contrast, of increasing our knowledge about minority members in thinly settled areas.

We thank colleagues at the Medical Sociology Unit and Bob Butcher, Mike Dalton, and Adrian Davis for advice on methodological issues relevant to this paper. We also thank our interviewers. More generally, on the substantive project involved here, we wish to acknowledge the vital contribution of Sheila Bhatt and Raj Bhopal.

Appendix 1

CALCULATION OF STANDARDISED WEIGHTS USING SPSS In order to compare weighted with unweighted tables, it may be useful to standardise weights so that they have a mean of 1 and so sum to the original sample size. This can be done using the SPSS ${ }^{\mathbf{x}}$ AGGREGATE and MATCH FILES procedures. ${ }^{15}$ AGGREGATE here sums the weights and the number of cases over the whole sample, and MATCH FILES adds these summed quantities to each record as follows:

Let WTRAW be raw weight $\mathrm{W}_{\mathrm{h}}$ WTSTAND be standardised weight $\mathrm{W}_{\mathrm{h}}{ }^{\star}$

Then the SPSS ${ }^{\mathrm{x}}$ commands are:

COMPUTE CONST $=1$

AGGREGATE OUTFILE $=$ TEM $/$ BREAK $=$ CONST $/$ SUM $=$ SUM $($ WTRAW $)$

SUMC $=\operatorname{sUM}($ CONST $)$

MATCH FILES TABLE $=$ TEM $/$ FILE $=\star / B$ BY CONST

COMPUTE WTSTAND $=$ WTRAW $\star$ SUMC $/$ SUM

The standardised weights are now implemented by the command

\section{WEIGHT BY WTSTAND}

which weights each raw weight by the sum of cases over the sum of the raw weights.

\section{Appendix 2}

CALCULATION OF THE LOSS OF EFFECTIVE SAMPLE SIZE DUE TO WEIGHTING AND ITS COMPUTATION USING SPSS ${ }^{\mathbf{x}}$

This appendix is in two parts, the first (a) addressing statisticians, the second (b) addressing computer users in general. The first part derives the rescaling factor by which to multiply the raw weights in order to obtain correct general estimates of the standard errors. (The formulas used by the SPSS ${ }^{x}$ WEIGHT command are correct under the assumptions of equal within stratum variances and no variation in means between strata). The second part gives the SPSS ${ }^{\mathbf{x}}$ commands required to do this. These again include the SPSS ${ }^{\mathbf{x}}$ procedures AGGREGATE and MATCH FILES. In this case AGGREGATE computes the sums of the weights and of the squares of the weights over the whole sample, and MATCH FILES adds these summed quantities on to each record. This enables the raw weight to be weighted by the sum of the raw weights over the sum of their squares.

a. Derivation of rescaling factor

The variance of the population weighted mean, conditional on the sample drawn, is estimated by

$$
\hat{\mathrm{V}}_{\mathrm{ps}}=\Sigma_{\mathrm{h}}\left(\mathrm{N}_{\mathrm{h}} / \mathrm{N}\right)^{2}\left(1-\mathrm{n}_{\mathrm{h}} / \mathrm{N}_{\mathrm{h}}\right) \hat{\mathrm{S}}_{\mathrm{h}}{ }^{2} / \mathrm{n}_{\mathrm{h}}
$$

(see Holt and Smith, ${ }^{16}$ equation 2; Kalton, ${ }^{17}$ p 49) 
where $\mathrm{n}_{\mathrm{h}}=$ sample size in stratum $\mathrm{h}$

$\mathrm{N}_{\mathrm{h}}=$ population size in stratum $\mathrm{h}$

$\mathrm{N}=$ total population $\left(=\Sigma_{\mathrm{h}} \mathrm{N}_{\mathrm{h}}\right)$

$\hat{\mathrm{S}}_{\mathrm{h}}{ }^{2}=$ estimated variance of respondents in stratum $h$

The weight, $W_{h}$, applied to stratum $h$ is the ratio of the proportion of the population in the stratum to the proportion of the sample in the stratum. Thus:

$$
\mathrm{W}_{\mathrm{h}}=\frac{\left(\mathrm{N}_{\mathrm{h}} / \mathrm{N}\right)}{\left(\mathrm{n}_{\mathrm{h}} / \mathrm{n}\right)}
$$

Ignoring the finite population correction (ie, when the sample is sufficiently small in relation to the population), we have:

$$
\hat{\mathrm{V}}_{\mathrm{ps}}=\frac{\Sigma_{\mathrm{h}} \mathrm{W}_{\mathrm{h}}^{2} \hat{\mathrm{S}}_{\mathrm{h}}^{2} \mathrm{n}_{\mathrm{h}}}{\mathrm{n}^{2}}=\frac{\Sigma_{\mathrm{h}} \mathrm{W}_{\mathrm{h}}^{2} \hat{\mathrm{S}}_{\mathrm{h}}^{2} \mathrm{n}_{\mathrm{h}}}{\left(\Sigma_{\mathrm{h}} \mathrm{W}_{\mathrm{h}} \mathrm{n}_{\mathrm{h}}\right)^{2}}
$$

(see also Collins and Hedges ${ }^{18}$ ).

If we can assume that the variable under study has the same standard deviation, $S$, in each stratum, the expression then becomes

$$
\frac{\hat{S}^{2} \Sigma_{h} W_{h}^{2} n_{h}}{\left(\Sigma_{h} W_{h} n_{h}\right)^{2}}
$$

The factor by which the sampling variance is increased (or, equivalently, the proportional loss in effective sample size) is then given by

$$
\frac{n \Sigma_{h} W_{h}^{2} n_{h}}{\left(\Sigma_{h} W_{h} n_{h}\right)^{2}}
$$

Under the condition that the variable under study has the same mean and standard deviation in each stratum the variance of the weighted mean is given in SPSS software by

$$
\hat{\mathbf{V}}_{\text {spss }}=\frac{\hat{\mathbf{S}}^{2}}{\left(\Sigma_{\mathrm{h}} \mathbf{W}_{\mathrm{h}} \mathrm{n}_{\mathrm{h}}-1\right)}
$$

where $S^{2}$ is the overall variance. This variance must be made equivalent to the variance of the weighted estimator. This is achieved (ignoring the -1 in the denominator of expression 2) by rescaling the weights $W_{h}$, to form new weights $W_{h}{ }^{\star}$

where

$$
W_{h}^{\star}=\frac{W_{h} \Sigma_{h} n_{h} W_{h}}{\Sigma_{h} n_{h} W_{h}^{2}}
$$

These new weights average less than 1 , and generally give a conservative approximation to the variance of the population weighted mean when stratum means differ but stratum variances do not differ significantly, as is the case with most of our variables.

b. SPSS $S^{x}$ commands to rescale the weights This calculation is easily carried out using the AGGREGATE procedure of SPSS ${ }^{\mathbf{x}}$ as follows:
Let WTRAW be raw weight $\mathrm{W}_{\mathrm{h}}$ WTSTAND be rescaled weight $\mathrm{W}_{\mathrm{h}}$

Then the SPSS ${ }^{\mathbf{x}}$ commands are:

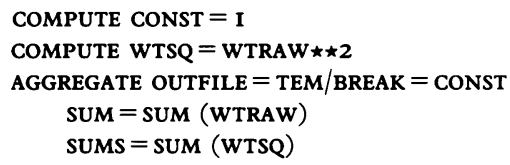

MATCH FILES TABLE $=$ TEM $/$ FILE $=\star /$ BY CONST COMPUTE WTSTAND $=$ WTRAW $\star S U M /$ SUMS

The rescaled weights are now implemented by the command:

WEIGHT BY WTSTAND

1 Brown C. Black and white Britain: the third PSI survey. London: Gower, 1984.

2 Nicoll A, Bassett $K$, Ulijaszek SJ. What's in a name? Accuracy of using surnames and forenames in ascribing Asian ethnic identity in English populations. $\tilde{f}$ Epidemiol Asian ethnic identity in English popu

3 Coldman AJ, Braun T, Gallagher RP. The classification of ethnic status using name information. $\mathcal{f}$ Epidemiol Community Health 1988; 42: 390-5.

4 Hoinville G, Jowell R. Survey research practice. London: Gower, 1985: 84

5 Todd J. Butcher R. Electoral registration in 1981. London OPCS, 1982

6 Ecob R. The sampling scheme, frame and procedures for the cohort studies. Glasgow: MRC Medical Sociology Unit, cohort studies. Glasgow: MR

7 Kalton G, Anderson DW. Sampling rare populations. $f R$ Stat Soc A 1986; 149: 65-82.

8 Goldstein H. Multilevel models in educational and social research. London: Griffin, 1987.

9 Williams R, Ecob R. The Asian midlife sample. Glasgow: MRC Medical Sociology Unit, 1990; Working Paper no 16.

10 Knudson RJ, Slatin RC, Lebowitz MD, Burrows B. The maximal expiratory flow-volume curve: normal standards, variability and effects of age. Am Rev Respir Dis 1976; 113: v87-600.

11 Vieweg BW, Hedlund JL. The General Health Questionnaire (GHQ): a comprehensive review. $f$ Operational Psychiatry 1983; 14: 74-81.

12 Cochrane R, Farrukh H, Stopes-Roe M. Measuring psychological disturbance in Asian immigrants to Britain. Soc Sci Med 1977; 11: 157-64.

13 Dalton M, Daghlian S. Housing needs, experiences and expectations of Glasgow's ethnic minority population: the role of housing associations. Glasgow: Scottish Ethnic Minorities Research Unit, 1989: 43.

14 Wilson PR, Elliot DJ. An evaluation of the Postcode Address File as a sampling frame and its use within OPCS. $\mathcal{F} R$ Stat Soc $A$ 1987; 150: 230-40.

15 SPSS Inc. SPS $S^{x}$ users' guide. New York: McGraw Hill.

6 Holt D, Smith TMF. Post stratification. $\mathcal{F} R$ Stat Soc $A$ 1979; 142: 33-46.

17 Kalton G. Compensating for missing survey data. Ann Arbor: Survey Research Center, University of Michigan, 1983.

18 Collins M, Hedges B. Variable sampling fractions and the effect of weighting. London: Social and Community effect of weighting. London: Social and Community
Planning Research, 1977; Methodological Working Paper Planning 4. 